\title{
Probes of the Mitochondrial cAMP-dependent Protein Kinase
}

\author{
Jennifer R. Shell and David S. Lawrence* \\ Departments of Chemistry, Chemical Biology and Medicinal Chemistry, and Pharmacology, \\ University of North Carolina, Chapel Hill, NC 27599
}

\begin{abstract}
The development of a fluorescent assay to detect activity of the mitochondrial cAMP-dependent protein kinase (PKA) is described. A peptide-based sensor was utilized to quantify the relative amount of PKA activity present in each compartment of the mitochondria (the outer membrane, the intermembrane space, and the matrix). In the process of validating this assay, we discovered that PKA activity is regulated by the protease calpain. Upon exposure of bovine heart mitochondria to digitonin, $\mathrm{Ca}^{2+}$, and a variety of electron transport chain inhibitors, the regulatory subunits of the PKA holoenzyme $\left(\mathrm{R}_{2} \mathrm{C}_{2}\right)$ are digested, releasing active catalytic subunits. This proteolysis is attenuated by calpain inhibitor I (ALLN).
\end{abstract}

\section{Keywords}

signal transduction; sensor; fluorescent peptide; cAMP-dependent protein kinase (PKA); calpain

\section{Introduction}

\begin{abstract}
Members of the protein kinase family have been implicated in numerous cell functions, ranging from ATP generation to cell growth and division.[1] Kinases catalyze the transfer of a phosphoryl group from ATP to the hydroxyl groups of serine, threonine, or tyrosine residues in proteins. The cAMP-dependent protein kinase (PKA) is a serine/threonine kinase that exists as an inactive tetrameric holoenzyme consisting of two regulatory subunits and two catalytic subunits. The conventional mode of activation of PKA involves the binding of cAMP to the regulatory subunits, causing release of the catalytic subunits, which then phosphorylate a myriad of proteins. [2,3] PKA is anchored to a variety of intracellular locations via interaction with A-kinase anchoring proteins (AKAPs).
\end{abstract}

PKA activity at the mitochondria is associated with the regulation of apoptosis, mitochondrial respiration, and ATP synthesis.[4-6] PKA phosphorylates the proapoptotic protein BAD, which prevents cell death.[5] PKA also phosphorylates apoptotic proteaseactivating factor (Apaf-1), which inhibits the formation of the apoptosome and activation of caspase-9.[7] In addition, PKA increases mitochondrial respiration via phosphorylation of subunits contained within complexes I and IV.[4] Although it is well known that PKA is present at the mitochondria, the relative amount of enzyme present in each compartment

(c) 2012 Elsevier B.V. All rights reserved.

"Corresponding author. The Departments of Chemistry, Chemical Biology and Medicinal Chemistry, and Pharmacology, Campus Box 3290, Kenan Laboratories, The University of North Carolina at Chapel Hill, Chapel Hill, NC 27599-3290, USA. Tel.: +1 919843

7100; fax: +1 919962 2388. lawrencd@ email.unc.edu (D.S. Lawrence)..

Publisher's Disclaimer: This is a PDF file of an unedited manuscript that has been accepted for publication. As a service to our customers we are providing this early version of the manuscript. The manuscript will undergo copyediting, typesetting, and review of the resulting proof before it is published in its final citable form. Please note that during the production process errors may be discovered which could affect the content, and all legal disclaimers that apply to the journal pertain. 
(outer membrane, intermembrane space, matrix) remains unclear. Orr and colleagues demonstrated that type II PKA is located on the outer membrane of mitochondria in male germ cells.[8] However, PKA has also been shown to be associated with the inner membrane/matrix.[9, 10] Most of these studies employed electron microscopy to pinpoint the suborganelle location of the holoenzyme. However, since the catalytic subunit can diffuse through membranes [11], holoenzyme location as assessed by electron microscopy may not represent the location of the active enzyme. Given this information we sought to develop an assay that would quantify the relative amounts of PKA activity present in each major compartment of the mitochondria.

\section{Development of a Fluorescent Sensor for Mitochondrial PKA Activity}

Fluorescent sensors of protein kinase activity furnish a direct means to assess catalytic action in a continuous fashion.[12] However, in many instances, the fluorescent response is modest, thereby necessitating the use of large amounts of sensor to ensure a measureable signal. Consequently, we sought to develop a sensor with a large dynamic range, thereby reducing the quantity of sensor required for signal detection and thus the perturbation on the biological system under scrutiny. We employed three coumarin derivatives as the kinaseresponsive fluorophores [13]. These fluorophores were appended to the N-terminus of peptides of the general structure coumarin-Aoc-GRTGRRFSYP-amide (1-3, Figure 1, Aoc = aminooctanoic acid). We anticipated that negatively charged fluorescent quenchers would interact with the positively charged peptide, resulting in the loss of coumarin fluorescence. However, upon phosphorylation the peptide interacts with a phosphoserine-binding 14-3-3 domain, displacing the quencher, and resulting in a burst of fluorescence (Scheme 1). Peptides 1 - 3 were screened with a variety of negatively charged dyes. Acid green 27 (4, Figure 1) furnishes a deep fluorescent quench as well as a dramatic PKA-induced fluorescence increase, with peptide 1 displaying a remarkable 152-fold fluorescence enhancement (Table 1).

We employed the strategy depicted in Figure 2 to assess the location of PKA activity in bovine heart mitochondria. Perhaps the most straightforward way to achieve this would be to subfractionate the mitochondria (i.e. separate the outer membrane, the intermembrane space, and the matrix) and assess the activity of each compartment. However, digitonin is typically used to remove the outer membrane and release the contents of the intermembrane space. Digitonin has been demonstrated to cause leakage of matrix proteins in bovine heart mitochondria,[14] thereby contaminating the intermembrane space fraction, and resulting in an inaccurate assessment of relative amount of protein. Therefore, intact bovine heart mitochondria were treated with cAMP, and PKA activity assessed utilizing the assay described above with peptide $\mathbf{1}$. Since the outer membrane of mitochondria is permeant to small molecules less than $5000 \mathrm{Da}$, including peptide 1, this measures the PKA activity at both the outer membrane and intermembrane space. Proteolysis of the outer membrane proteins with trypsin prior to assessing PKA activity distinguishes outer membrane activity from intermembrane space activity. Sonication of whole mitochondria followed by treatment with cAMP affords the total PKA activity (outer membrane, intermembrane space, matrix). With information in hand, the relative percentage of PKA activity can be calculated for each major compartment: $85 \%$ in the matrix, $6 \%$ in the intermembrane space, and $9 \%$ on the outer membrane.[14]

\section{Proteolytic Regulation of Mitochondrial PKA}

While attempting to subfractionate bovine heart mitochondria with digitonin we observed leakage of matrix proteins and proteolysis of both isoforms of the regulatory subunits (RI and RII).[15] By contrast, the catalytic subunit (C) remained intact. Since multiple isoforms 
of calpain, a $\mathrm{Ca}^{2+}$-activated protease, have recently been reported to reside in the mitochondria,[16, 17] we investigated whether this protease played a role in the digestion of the PKA R subunits. Indeed, attenuation of digitonin-induced R subunit proteolysis was observed upon the addition of calpain inhibitor I (N-acetyl-Leu-Leu-Nle-al, ALLN) (Figure $3 a)$. Furthermore, addition of $\mathrm{Ca}^{2+}$ enhances this proteolysis, consistent with involvement of a $\mathrm{Ca}^{2+}$-dependent protease (Figure $3 \mathrm{~b}$ ). We observed direct activation of mitochondrial calpain by digitonin and $\mathrm{Ca}^{2+}$ using a fluorescent methyl-coumarin substrate (Figure $3 \mathrm{c}$ ).

To further confirm this calpain-mediated selective proteolysis, isolated $\mathrm{R}$ and $\mathrm{C}$ subunits were subjected to calpain I digestion.[15] Both are prone to digestion; however, the amount of $\mathrm{CaCl}_{2}$ drastically affects selectivity. The $\mathrm{R}$ subunit is selectively digested with $10 \mu \mathrm{M}$ $\mathrm{CaCl}_{2}$; whereas the $\mathrm{C}$ subunit also suffers partial proteolysis at $\mathrm{Ca}^{2+}$ concentrations $\geq 100$ $\mu \mathrm{M}$ (Figure $4 \mathrm{a})$. This suggests that, under physiological $\mathrm{Ca}^{2+}$ concentrations $(<100 \mu \mathrm{M})$, the $\mathrm{R}$ subunit can be selectively digested, thereby releasing free $\mathrm{C}$ subunit. The holoenzyme $\mathrm{R}_{2} \mathrm{C}_{2}$ was also subjected to digestion by calpain I. Interestingly, proteolysis of the $\mathrm{R}$ subunit, but not the $\mathrm{C}$ subunit, even occurs at $100 \mu \mathrm{M} \mathrm{CaCl}_{2}$, implying that the $\mathrm{C}$ subunit is more resistant to proteolysis while in holoenzyme form (Figure 4b). One possible explanation is the formation of an $\mathrm{R}$ subunit fragment that protects the $\mathrm{C}$ subunit from calpain-mediated proteolysis.

We also investigated whether this selective $\mathrm{R}$ subunit proteolysis releases active $\mathrm{C}$ subunit from the mitochondria into the supernatant. Mitochondria were treated with either cAMP (2 $\mathrm{mM})$ or $\mathrm{Ca}^{2+}(100 \mu \mathrm{M})$ in the presence of soluble adenylate cyclase inhibitor KH7 $(25 \mu \mathrm{M})$, centrifuged, and the supernatant examined for release of active $\mathrm{C}$ subunit. Western blot analysis of the supernatant shows that $\mathrm{C}$ subunit is released into the supernatant upon exposure to either $\mathrm{Ca}^{2+}$ or cAMP. Furthermore, the calpain inhibitor ALLN attenuates $\mathrm{Ca}^{2+}$ induced release of $\mathrm{C}$ subunit into the supernatant, consistent with a calpain-dependent process (Figure 5). Finally, we confirmed that the released $\mathrm{C}$ subunit is catalytically active.

Since $\mathrm{Ca}^{2+}$ is a known inducer of the mitochondrial pore transition (MPT)[18], we decided to investigate whether other reagents that induce MPT also activate PKA in a calpaindependent fashion. Both electron transport chain inhibitors and uncouplers have been linked to induction of MPT[19-22]. Mitochondria were exposed to rotenone (complex I inhibitor), antimycin $\mathrm{A}$ (complex III inhibitor), sodium azide (complex IV inhibitor), oligomycin $\left(\mathrm{F}_{1} \mathrm{~F}_{0}\right.$ ATPase inhibitor) as well as the uncoupler CCCP in the presence and absence of ALLN, centrifuged, and the supernatant examined for released $\mathrm{C}$ subunit by Western blot. Exposure to rotenone, azide and CCCP elicit the largest enhancements in PKA activity, all of which are attenuated by ALLN (Figure 6). Antimycin A and oligomycin also induced PKA activity, but to a lesser extent. In addition, the activity elicited by oligomycin proved to be calpain independent (Figure 6).

\section{Conclusion}

A PKA sensor with a large dynamic range (a phosphorylation-induced 152-fold enhancement in fluorescence) has been used to assess the suborganelle distribution of mitochondrial PKA activity. We found that PKA activity predominantly resides in the matrix $(85 \%)$, although detectable amounts are present on the outer membrane $(9 \%)$ and in the intermembrane space (6\%).[14] We note that a variety of genetically-encoded protein kinase sensors have been described, most commonly by a mechanism in which phosphorylation induces conformational change and a subsequent florescent readout via a pair of FRET-based green fluorescent proteins.[23] Although a detailed comparison of the relative attributes of peptide-based and genetically-encoded sensors is beyond scope of this brief review, we do note that peptide-based systems can readily be prepared with extremely 
bright fluorophores that emit between the long UV and the near IR. Furthermore, the large dynamic range enjoyed by the sensor described in this study exemplifies the possibilities inherent in a system that is essentially non-fluorescent in its unphosphorylated state.

During the validation of this assay, we discovered that PKA activity is regulated in a calpain-dependent fashion.[15] Furthermore, metabolic inhibitors elicit enhanced PKA activity in bovine heart mitochondria by this mechanism. Azide (complex IV inhibitor) and rotenone (complex I inhibitor) are the most robust calpain-mediated activators of PKA identified in this study. Interestingly, treatment of neurons and cadiomyocytes with azide and rotenone is known to result in the activation of calpain. [24, 25] Consequently, it is tempting to speculate that stress-induced MPT and $\mathrm{Ca}^{2+}$ release [26] promotes the activation of calpain, the subsequent selective degradation of the R subunits of the PKA holoenzyme, and release of active $C$ subunit. The induction of PKA activity by mitochondrial stress could be a protective mechanism since PKA action is known to inhibit apoptosis [27] and promote enhanced respiration rates $[28,29]$.

\section{Abbreviations}

ALLN, calpain inhibitor I N-acetyl-Leu-Leu-Nle-CHO; C subunit, catalytic subunit; CCCP, chlorophenylhydrazone

\section{References}

1. Manning G, Whyte DB, Martinez R, Hunter T, Sudarsanam S. The protein kinase complement of the human genome. Science. 2002; 298:1912-1934. [PubMed: 12471243]

2. Gullingsrud J, Kim C, Taylor SS, McCammon JA. Dynamic binding of PKA regulatory subunit RI alpha. Structure. 2006; 14:141-149. [PubMed: 16407073]

3. Kim C, Xuong NH, Taylor SS. Crystal structure of a complex between the catalytic and regulatory (RIalpha) subunits of PKA. Science. 2005; 307:690-696. [PubMed: 15692043]

4. Acin-Perez R, Salazar E, Kamenetsky M, Buck J, Levin LR, Manfredi G. Cyclic AMP produced inside mitochondria regulates oxidative phosphorylation. Cell Metab. 2009; 9:265-276. [PubMed: 19254571]

5. Feliciello A, Gottesman ME, Avvedimento EV. cAMP-PKA signaling to the mitochondria: protein scaffolds, mRNA and phosphatases. Cell Signal. 2005; 17:279-287. [PubMed: 15567059]

6. Technikova-Dobrova Z, Sardanelli AM, Speranza F, Scacco S, Signorile A, Lorusso V, Papa S. Cyclic adenosine monophosphate-dependent phosphorylation of mammalian mitochondrial proteins: enzyme and substrate characterization and functional role. Biochemistry. 2001; 40:1394113947. [PubMed: 11705384]

7. Martin MC, Allan LA, Lickrish M, Sampson C, Morrice N, Clarke PR. Protein kinase A regulates caspase-9 activation by Apaf-1 downstream of cytochrome c. J Biol Chem. 2005; 280:1544915455. [PubMed: 15703181]

8. Lieberman SJ, Wasco W, MacLeod J, Satir P, Orr GA. Immunogold localization of the regulatory subunit of a type II cAMP-dependent protein kinase tightly associated with mammalian sperm flagella. J Cell Biol. 1988; 107:1809-1816. [PubMed: 2972731]

9. Papa S, Sardanelli AM, Scacco S, Technikova-Dobrova Z. cAMP-dependent protein kinase and phosphoproteins in mammalian mitochondria. An extension of the cAMP-mediated intracellular signal transduction. FEBS Lett. 1999; 444:245-249. [PubMed: 10050768]

10. Schwoch G, Trinczek B, Bode C. Localization of catalytic and regulatory subunits of cyclic AMPdependent protein kinases in mitochondria from various rat tissues. Biochem J. 1990; 270:181188. [PubMed: 2396978]

11. Harootunian AT, Adams SR, Wen W, Meinkoth JL, Taylor SS, Tsien RY. Movement of the free catalytic subunit of cAMP-dependent protein kinase into and out of the nucleus can be explained by diffusion. Mol Biol Cell. 1993; 4:993-1002. [PubMed: 8298196] 
12. Lawrence DS, Wang Q. Seeing is believing: peptide-based fluorescent sensors of protein tyrosine kinase activity. Chembiochem. 2007; 8:373-378. [PubMed: 17243187]

13. Burnette B, Batra PP. A combination of methods for the preparation of highly intact mitoplasts from beef heart mitochondria. Anal Biochem. 1985; 145:80-86. [PubMed: 2988371]

14. Agnes RS, Jernigan F, Shell JR, Sharma V, Lawrence DS. Suborganelle sensing of mitochondrial cAMP-dependent protein kinase activity. J. Am Chem Soc. 2010; 132:6075-6080. [PubMed: 20380406]

15. Shell JR, Lawrence DS. Proteolytic regulation of the mitochondrial cAMP-dependent protein kinase. Biochemistry. 2012; 51:2258-2264. [PubMed: 22385295]

16. Arrington DD, Van Vleet TR, Schnellmann RG. Calpain 10: a mitochondrial calpain and its role in calcium-induced mitochondrial dysfunction. Am J Physiol Cell Physiol. 2006; 291:C1159-1171. [PubMed: 16790502]

17. Badugu R, Garcia M, Bondada V, Joshi A, Geddes JW. N terminus of calpain 1 is a mitochondrial targeting sequence. J Biol Chem. 2008; 283:3409-3417. [PubMed: 18070881]

18. Halestrap AP. What is the mitochondrial permeability transition pore? J Mol Cell Cardiol. 2009; 46:821-831. [PubMed: 19265700]

19. Isenberg JS, Klaunig JE. Role of the mitochondrial membrane permeability transition (MPT) in rotenone-induced apoptosis in liver cells. Toxicol Sci. 2000; 53:340-351. [PubMed: 10696782]

20. Pastorino JG, Snyder JW, Serroni A, Hoek JB, Farber JL. Cyclosporin and carnitine prevent the anoxic death of cultured hepatocytes by inhibiting the mitochondrial permeability transition. J Biol Chem. 1993; 268:13791-13798. [PubMed: 8314748]

21. Seaton TA, Cooper JM, Schapira AH. Cyclosporin inhibition of apoptosis induced by mitochondrial complex I toxins. Brain Res. 1998; 809:12-17. [PubMed: 9795106]

22. Zoratti M, Szabo I. The mitochondrial permeability transition. Biochim Biophys Acta. 1995; 1241:139-176. [PubMed: 7640294]

23. Tamtama M, Hung YP, Yellen G. Optogenetic reporters: fluorescent protein-based geneticallyencoded indicators of signaling and metabolism in the brain. Prog. Brain Res. 2012; 196:235-263. [PubMed: 22341329]

24. Chen MJ, Yap YW, Choy MS, Koh CH, Seet SJ, Duan W, Whiteman M, Cheung NS. Early induction of calpains in rotenone-mediated neuronal apoptosis. Neurosci Lett. 2006; 397:69-73. [PubMed: 16412576]

25. Kositprapa C, Zhang B, Berger S, Canty JM Jr. Lee TC. Calpain-mediated proteolytic cleavage of troponin I induced by hypoxia or metabolic inhibition in cultured neonatal cardiomyocytes. Mol Cell Biochem. 2000; 214:47-55. [PubMed: 11195789]

26. Bernardi P, Rasola A. Calcium and cell death: the mitochondrial connection. Subcell. Biochem. 2007; 45:481-506. [PubMed: 18193649]

27. Sastry KS, Karpova Y, Prokopovich S, Smith AJ, Essau B, Gersappe A, Carson JP, Weber MJ, Register TC, Chen YQ, Penn RB, Kulik G. Epinephrine protects cancer cells from apoptosis via activation of cAMP-dependent protein kinase and BAD phosphorylation. J. Biol. Chem. 2007; 282:14094-14100. [PubMed: 17353197]

28. Technikova-Dobrova Z, Sardanelli AM, Speranza F, Scacco S, Signorile A, Lorusso V, Papa, S. S. Cyclic adenosine monophosphate-dependent phosphorylation of mammalian mitochondrial proteins: enzyme and substrate characterization and functional role. Biochemistry. 2001; 40:13941-13947. [PubMed: 11705384]

29. Acin-Perez R, Salazar E, Kamenetsky M, Buck J, Levin LR, Manfredi, G. G. Cyclic AMP produced inside mitochondria regulates oxidative phosphorylation. Cell Metab. 2009; 9:265-276. [PubMed: 19254571] 


\section{Highlights}

- Development of a fluorescent sensor for PKA with a large dynamic range

- Determination of the suborganelle location of mitochondrial PKA activity

- Discovery of a proteolytic regulation of mitochondrial PKA activity 
<smiles>CCN(CC)c1ccc2cc(C(=O)NOCCOCCO)c(=O)oc2c1</smiles><smiles>CCOC(=O)NC(=O)CCCN1c2cc3oc(=O)c(C(=O)OCC)cc3cc2C(C)CC1(C)C</smiles><smiles>O=C(NC(=O)c1cc2cc3c4c(c2oc1=O)CCCN4CCC3)OCc1ccccc1</smiles><smiles>CCCCc1ccc(Nc2ccc(Nc3ccc(CCCC)cc3[S+](=O)(=O)[O-])c3c2C(=O)c2ccccc2C3=O)c([S+](=O)[O-])c1</smiles>

Fig. 1.

Structures of the coumarin derivatives $\mathbf{1}-\mathbf{3}$ of the general form fluorophore-AocGRTGRRFSYP-amide. The fluorescent quencher Acid Green 27 (4) was identified from a library of forty-seven dyes. Reprinted with permission from [14]. Copyright 2010 American Chemical Society. 


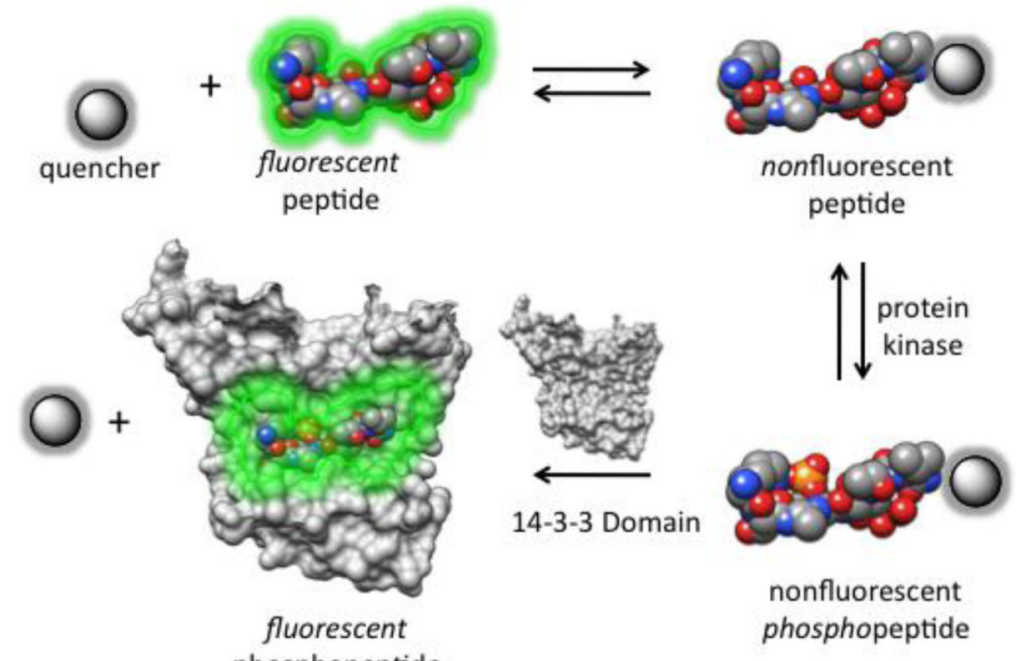

Scheme 1.

Protein kinase-catalyzed phosphorylation of a fluorescently quenched peptide generates a fluorescent response in the presence of the phosphoSer-binding 14-3-3 domain. Reprinted with permission from [14]. Copyright 2010 American Chemical Society. 


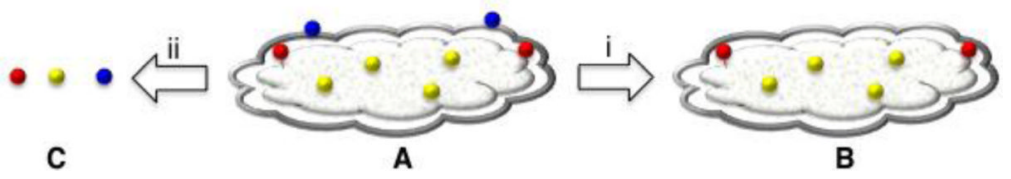

Fig. 2.

Strategy for assessing PKA activity on the outer membrane (blue), in the intermembrane space (red) and in the matrix (yellow). PKA activity of intact mitochondria (A) is due to enzyme present on the outer membrane and in the intermembrane space. Trypsinized (i) mitochondria (B) lack outer membrane proteins and thus only intermembrane space PKA is present. Sonicated (ii) mitochondria $(\mathbf{C})$ furnishes enzyme from all three compartments and thus represents total mitochondrial PKA. Reprinted with permission from [14]. Copyright 2010 American Chemical Society. 
A

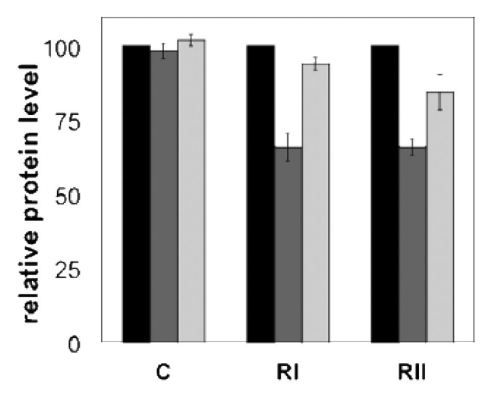

C
B

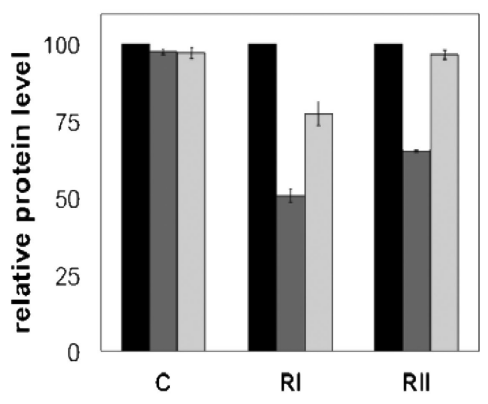

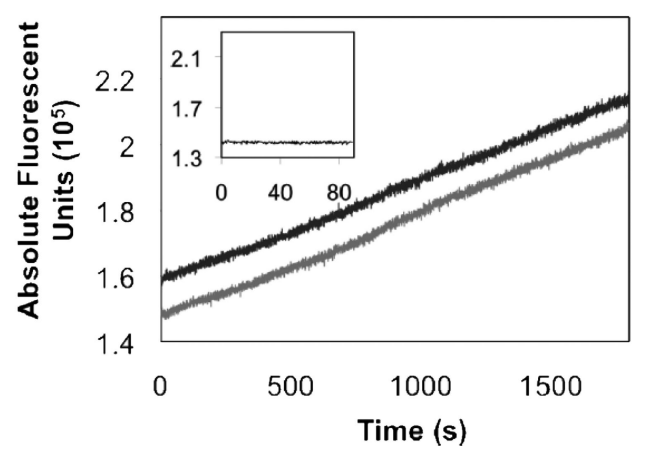

Fig. 3.

Digitonin and $\mathrm{Ca}^{2+}$-induced digestion of mitochondrial PKA. A. Bovine heart mitochondria incubated with digitonin in the presence or absence of ALLN where black bar = untreated mitochondria, dark gray bar = digitonin-exposed mitochondria, and the light gray bar = digitonin and ALLN (calpain inhibitor I)-exposed mitochondria. B. Bovine heart mitochondria incubated with digitonin and $\mathrm{CaCl}_{2}$ in the presence or absence of ALLN where black bar = untreated mitochondria, dark gray bar $=$ digitonin $/ \mathrm{CaCl}_{2}$-exposed mitochondria, and the light gray bar = digitonin/ $\mathrm{CaCl}_{2}$ and $\mathrm{ALLN}$ (calpain inhibitor I)-exposed mitochondria. C. Calpain activity (assessed utilizing the fluorescent substrate N-succinylLeu-Tyr-7-amido-4-methylcoumarin) from bovine heart mitochondria incubated with digitonin (black trace), digitonin and $\mathrm{CaCl}_{2}$ (gray trace), or buffer alone (inset). Reprinted with permission from [15]. Copyright 2012 American Chemical Society. 
A

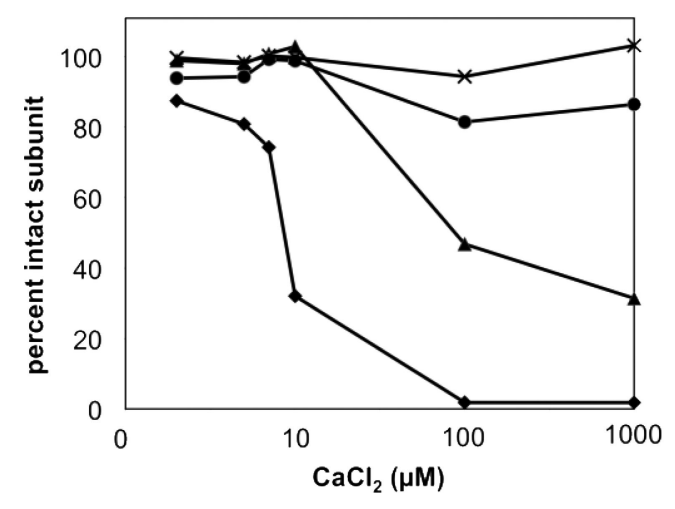

B

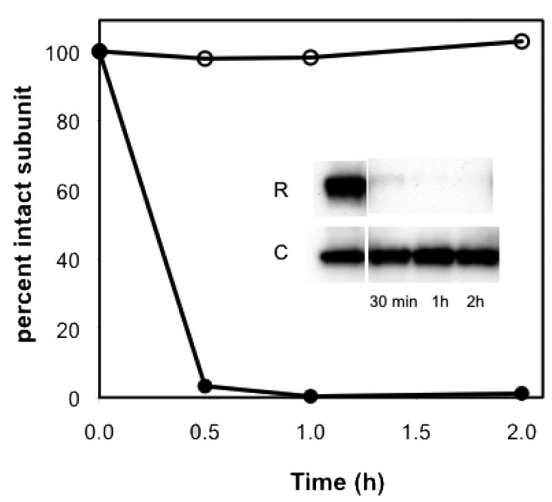

Fig. 4.

Calpain digestion of $\mathrm{C}, \mathrm{R}$, and $\mathrm{R}_{2} \mathrm{C}_{2}$. A. Calpain 1 was added to $\mathrm{C}$ or $\mathrm{R}$ (I and II) subunit in the presence or absence of ALLN. The reaction was initiated by the addition of variable concentrations of $\mathrm{CaCl}_{2}$, and incubated at $37^{\circ} \mathrm{C}$ for $20 \mathrm{~min}$ : $\mathrm{R}$ subunit $(\boldsymbol{\nabla}), \mathrm{C}$ subunit $(\mathbf{\Delta})$, $\mathrm{R}$ subunit and $\operatorname{ALLN}(\bullet)$, and $\mathrm{C}$ subunit and $\operatorname{ALLN}(\mathbf{X})$. B. Calpain 1 was added to the $\mathrm{R}_{2} \mathrm{C}_{2}$ holoenzyme in the presence of $100 \mu \mathrm{M} \mathrm{CaCl}_{2}$ for $0.5,1.5$, and $2.0 \mathrm{~h}$ and the $\mathrm{C}(\mathrm{O})$ and $\mathrm{R}(\bullet)$ subunits subsequently quantified via western blot analysis (inset). Adapted with permission from [15]. Copyright 2012 American Chemical Society. 
A

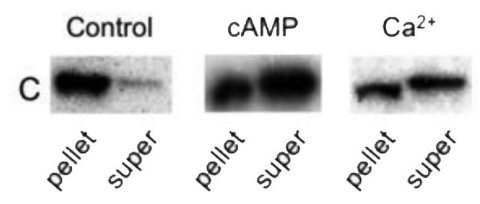

B

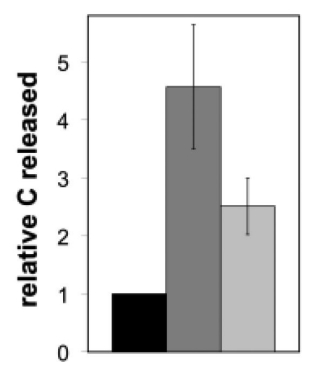

Fig. 5.

$\mathrm{Ca}^{2+}$-induced PKA activation: release of active $\mathrm{C}$ subunit. A. Mitochondria were treated with cAMP or $\mathrm{CaCl}_{2}$, centrifuged, and the pellet and supernatant processed for western blot analysis. B. Mitochondria were incubated with the soluble adenylate cyclase inhibitor KH7 for $30 \mathrm{~min}$, then treated with $\mathrm{CaCl}_{2}$ in the presence or absence of ALLN, centrifuged, and the supernatant analyzed for $\mathrm{C}$ subunit by western blot. Quantification of untreated (black bar), $\mathrm{Ca}^{2+}$-exposed (dark gray bar), and $\mathrm{Ca}^{2+} / \mathrm{ALLN}$-exposed (light gray bar) mitochondria. Adapted with permission from [15]. Copyright 2012 American Chemical Society. 


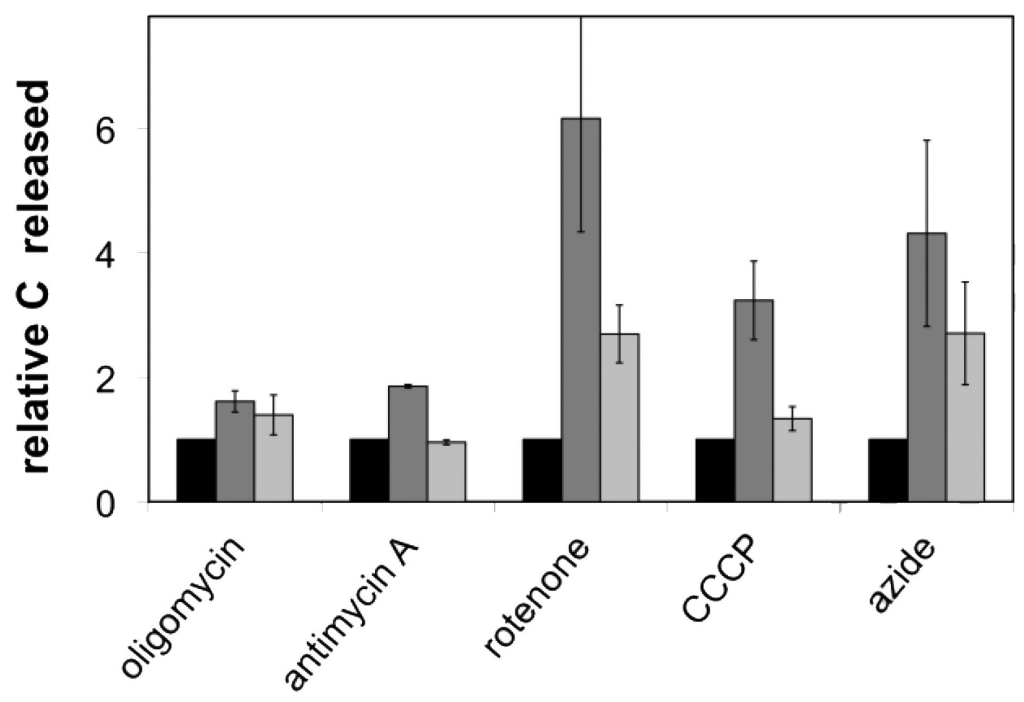

Fig. 6.

Metabolic inhibitors induce activation of PKA in a calpain-dependent fashion. Mitochondria were exposed to oligomycin $(5 \mu \mathrm{M})$, antimycin A $(5 \mu \mathrm{M})$, rotenone $(10 \mu \mathrm{M}), \mathrm{CCCP}(5$ $\mu \mathrm{M})$, or sodium azide $(2 \mathrm{mM})$ in the presence or absence of ALLN $(500 \mu \mathrm{M})$ for $30 \mathrm{~min}$ at $37{ }^{\circ} \mathrm{C}$ and subsequently centrifuged. The supernatants were analyzed by western blot for the presence of the $\mathrm{C}$ subunit. The relative amount of $\mathrm{C}$ subunit released from untreated (black bar), metabolic inhibitor-exposed (gray bar), and metabolic inhibitor/ALLN-exposed mitochondria. Reprinted with permission from [15]. Copyright 2012 American Chemical Society. 


\section{Table 1}

Photophysical properties, fluorescent fold increase, $K_{\mathrm{m}}$, and $V_{\max }$ for the PKA-catalyzed phosphorylation of sensors 1 - $\mathbf{3}$ (where sensor = Fluorophore-Aoc-GRTGRRFSYP-amide). Kinetic properties were acquired in the presence of quencher 4 and the 14-3-3 domain. Reprinted with permission from [14]. Copyright 2010 American Chemical Society.

\begin{tabular}{|cccc|}
\hline Sensor $\left(\boldsymbol{\lambda}_{\text {ex }} / \boldsymbol{\lambda}_{\text {em }}\right)$ & Fluorescent Fold-Increase & $\boldsymbol{K}_{\mathbf{m}}(\boldsymbol{\mu M})$ & $\boldsymbol{V}_{\max }(\boldsymbol{\mu} \mathbf{m o l} / \mathbf{m i n} \cdot \mathbf{m g})$ \\
\hline $\mathbf{1}(420 / 475 \mathrm{~nm})$ & 152 & $2.2 \pm 0.1$ & $0.53 \pm 0.03$ \\
$\boldsymbol{2}(437 / 477 \mathrm{~nm})$ & 150 & $1.9 \pm 0.1$ & $0.34 \pm 0.04$ \\
$\mathbf{3}(450 / 490 \mathrm{~nm})$ & 28 & $6.2 \pm 0.1$ & $0.20 \pm 0.09$ \\
\hline
\end{tabular}

